\title{
Dopamine Modulates the Susceptibility of Striatal Neurons to 3-Nitropropionic Acid in the Rat Model of Huntington's Disease
}

\author{
David S. Reynolds, Rebecca J. Carter, and A. Jennifer Morton \\ Department of Pharmacology, University of Cambridge, Cambridge CB2 1QJ, United Kingdom
}

Huntington's disease (HD) is a progressive neurodegenerative disorder characterized by chorea, psychiatric disturbances, and dementia. The striatum is the primary site of neuronal loss in HD; however, neither the mechanism of neurodegeneration nor the underlying cause of the selectivity for the striatum is understood. Chronic systemic injection of 3-nitropropionic acid (3-NP) into rats induces bilateral striatal lesions with many neuropathological features of HD and is widely used as a model of HD. In this study we examine the role striatal dopamine plays in 3-NP-induced striatal toxicity.

The effect of elevated striatal dopamine levels on 3-NP toxicity was examined by using acute administration of methamphetamine. After $7 \mathrm{~d}$ of 3-NP treatment, a single low dose of methamphetamine markedly increased the frequency of striatal lesion formation. This effect was mediated via dopamine receptors because it could be blocked by the administration of

Huntington's disease (HD) is a neurodegenerative disorder for which there is no treatment and that progresses relentlessly until death (Harper, 1996). The primary brain region affected in HD is the striatum; however, the mechanism underlying the selective loss of neurons from the striatum is not well understood.

Several animal models for HD exist (Coyle and Schwarcz, 1976; McGeer and McGeer, 1976; Beal et al., 1986), the most recent being the chronic 3-nitropropionic acid (3-NP) model (Beal et al., 1993; Brouillet et al., 1993, 1995). 3-NP is a mitochondrial toxin that causes striatal neuropathology similar to that seen in HD (Beal et al., 1993; Bossi et al., 1993). A major advantage of this model over other models of HD is that the lesions that are produced are bilateral and striatal-specific, and they develop spontaneously after systemic administration of 3-NP. However, as in HD, the factors mediating the selective toxicity of 3-NP to striatal neurons are unknown.

One popular theory for the striatum selective neuronal loss after 3-NP treatment is that an energy deficiency makes striatal neurons more vulnerable to the neurotoxic effects of endogenous glutamate, thus allowing excitotoxicity to occur without an increase of glutamate to "excitotoxic" levels (Novelli et al., 1988; Simpson and Isacson, 1993). Indeed, a number of studies have shown that factors important in excitotoxicity, such as glutamate

Received July 1, 1998; revised Aug. 25, 1998; accepted Sept. 15, 1998

This work was supported by grants from the Wellcome Trust and the Hereditary Disease Foundation. We thank Mr. Roger Hart for excellent photography and Mrs. Wendy Leavens for expert technical assistance.

Correspondence should be addressed to Dr. A. Jennifer Morton, Department of Pharmacology, University of Cambridge, Tennis Court Road, Cambridge CB2 1QJ, United Kingdom.

Copyright (C) 1998 Society for Neuroscience $\quad 0270-6474 / 98 / 1810116-12 \$ 05.00 / 0$ dopamine receptor antagonists. The effect of decreased striatal dopamine on 3-NP toxicity was examined by lesioning the nigrostriatal dopamine input to one striatum $7 \mathrm{~d}$ before 3-NP treatment was started. Removal of the dopamine input protected the denervated striatum from the neurotoxic effects of systemic 3-NP but did not prevent the formation of lesions in the intact striatum. Thus the formation of 3-NP lesions is critically dependent on an intact dopamine input.

Our data show that dopamine plays an important role in the formation of 3-NP lesions. We suggest that modulation of the dopaminergic system should be reevaluated as a potential drug target in the treatment for HD.

Key words: 3-nitropropionic acid; dopamine; 6-hydroxydopamine; rat; neurotoxicity; Huntington's disease; unilateral; striatum

and nitric oxide (NO), play an important role in 3-NP toxicity (Beal et al., 1993; Fu et al., 1995a; Schulz et al., 1995). However, the actions of neither glutamate nor NO, alone or in combination, fully explain the sensitivity of striatal neurons to systemically administered 3-NP. Further, neither glutamate nor NO is found exclusively in the striatum, but both are also present in regions of the brain that are not vulnerable to 3-NP (Cotman et al., 1987; Bredt et al., 1990). This suggests that some additional factor mediates the selectivity of the neurotoxic action of 3-NP on striatal neurons.

Although there are a large number of neuroactive substances in the striatum that might be involved in 3-NP toxicity, one of the best candidates is dopamine. Dopamine is released in the striatum from nigrostriatal terminals (Björkland and Lindvall, 1984) and is neurotoxic after direct injection into the striatum (Filloux and Townsend, 1993; Ben-Shachar et al., 1995; Hastings et al., 1996). Further, it has been shown that the administration of amphetamine (which increases striatal dopamine levels) potentiates 3-NP toxicity after the administration of a large single dose of 3-NP (Bowyer et al., 1996). However, a possible role for dopamine in the neurotoxicity after chronic low-dose 3-NP treatment has not been examined.

In this study we examined the effects of altering striatal dopamine levels on the neurotoxicity induced by chronic 3-NP treatment. We found that increased striatal dopamine release potentiated the formation of striatal 3-NP lesions and that decreased dopamine levels prevented lesion formation in the striatum. Our data strongly support the suggestion of a central role for dopamine in the formation of striatal lesions in 3-NP-intoxicated animals. 


\section{MATERIALS AND METHODS}

Animals. Female Sprague Dawley rats (200-250 gm) were used for all experiments. All rats were housed under standard conditions (12 hr light/dark cycle) with free access to food and water.

Drugs. 6-Hydroxydopamine (6-OHDA) was dissolved in $0.9 \%$ saline and $0.1 \%$ ascorbic acid and diluted to a concentration of $2 \mathrm{mg} / \mathrm{ml}$. 3-NP for injection was dissolved in PBS (100 mM), and the $\mathrm{pH}$ was adjusted to 7.4 with $5 \mathrm{~N}$ sodium hydroxide. Methamphetamine, $\mathrm{SCH} 23390$, and pargyline were dissolved in PBS, and sulpiride was dissolved in $1 \%$ aqueous lactic acid $(50 \mathrm{mg} / \mathrm{ml})$ and then diluted in PBS. All drugs were supplied by Sigma (Poole, UK).

Unilateral 6-OHDA lesions of the medial forebrain bundle. At $60 \mathrm{~min}$ before lesioning, rats $(n=11)$ received $35 \mathrm{mg} / \mathrm{kg}$ pargyline by intraperitoneal injection. Rats were then anesthetized with Avertin $(10 \mathrm{ml} / \mathrm{kg}$, i.p.) and placed in a stereotaxic frame (Kopf, Tujunga, CA) with the incisor bar $5 \mathrm{~mm}$ above the interaural line. 6-OHDA $(8 \mu \mathrm{g})$ was injected into the left medial forebrain bundle at a constant rate over $8 \mathrm{~min}$. The coordinates used were posterior $2.2 \mathrm{~mm}$ and lateral $1.5 \mathrm{~mm}$ from the bregma and ventral $7.9 \mathrm{~mm}$ from the dura mater, according to the atlas of Pellegrino and Cushman (1967). After the injection the needle was left in situ for $2 \mathrm{~min}$ before being slowly withdrawn, and the incision was closed with interrupted silk sutures.

Chronic 3-NP treatment. Two different protocols were used for the administration of 3-NP. For the 3-NP/methamphetamine experiments, rats received daily subcutaneous injections of either $3-\mathrm{NP}[12 \mathrm{mg} / \mathrm{kg}$ per day $(n=42)$ ] or PBS $(n=4)$ for $7 \mathrm{~d}$. On the seventh day, $4 \mathrm{hr}$ after their last 3-NP injection, 34 of the rats were given an intraperitoneal injection of either methamphetamine $(5 \mathrm{mg} / \mathrm{kg} ; n=15)$ or saline $(n=19)$. The remaining eight rats were given an intraperitoneal injection of methamphetamine $(5 \mathrm{mg} / \mathrm{kg}) 24 \mathrm{hr}$ after the last $3-\mathrm{NP}$ injection. All salinetreated rats received methamphetamine $4 \mathrm{hr}$ after the last saline injection. One of the methamphetamine-treated rats displayed no druginduced behavioral changes of any kind and was excluded from the study. All of the other animals were allowed to recover for a further $7 \mathrm{~d}$ before death.

3-NP treatment of 6-OHDA-lesioned rats $(n=11)$ began $7 \mathrm{~d}$ after lesioning. A stepwise protocol was used, with the dose of 3-NP, from an initial dose of $12 \mathrm{mg} / \mathrm{kg}$, increasing by $3 \mathrm{mg} / \mathrm{kg}$ every $4 \mathrm{~d}$ until the behavioral symptoms consistent with lesion formation were observed. The development of ataxia, piloerection, and hind limb recumbency was used as an index of striatal lesion formation (Gould and Gustine, 1982; Hamilton and Gould, 1987). On the day these behaviors appeared, 3-NP treatment was stopped. Rats were killed $7 \mathrm{~d}$ later.

A control group of unlesioned rats $(n=22)$ was treated in parallel with 3 -NP, and a second group of unlesioned rats $(n=8)$ was used as a vehicle control group. Vehicle-treated rats received treatment until all 3-NPtreated rats had developed the behavioral symptoms of lesion formation.

Administration of selective $D_{1}$ and $D_{2}$ dopaminergic antagonists. The role of dopamine receptors was examined by pretreating the rats with a selective $\mathrm{D}_{1}$ (SCH23390) (Bischoff et al., 1986; Hollis and Strange, 1992) or $\mathrm{D}_{2}$ (sulpiride) antagonist before methamphetamine administration. Rats for the dopamine antagonist study were treated for 1 week with 3 -NP at a dose of $12 \mathrm{mg} / \mathrm{kg}(n=30)$. On the final day of 3-NP treatment, rats were divided into three groups of 10 animals and given single injections of the $\mathrm{D}_{1}$ antagonist SCH23390 $\left(100 \mu \mathrm{g} / \mathrm{kg}\right.$, i.p.), the $\mathrm{D}_{2}$ antagonist sulpiride $(200 \mathrm{mg} / \mathrm{kg}$, i.p.), or both antagonists together.

All rats were given their final 3-NP injection $4 \mathrm{hr}$ before methamphetamine injection. Sulpiride has a slow onset of action (Fujiwara, 1992) and hence was given $5 \mathrm{hr}$ before methamphetamine injection. SCH23390 was administered $1 \mathrm{hr}$ before methamphetamine injection. All rats then received $5 \mathrm{mg} / \mathrm{kg}$ methamphetamine, and behavioral changes were observed. All rats were killed 1 week later.

Drug-induced behavioral changes. The behavioral changes induced by the administration of methamphetamine, SCH23390, or sulpiride were observed and recorded until drug-induced behaviors had subsided; this generally took 3-4 hr. Drug-induced behaviors were classified into several categories: hyperactivity, stereotypical sniffing and head bobbing, and piloerection. Gait alterations were classified into one of two categories: wobbly gait (uncoordinated use of the back legs and sideways falling) and hind limb recumbency (legs splayed out to either side).

A measure of catalepsy induced by either sulpiride or SCH23390 was obtained by placing the hind legs of the rat on a platform $5 \mathrm{~cm}$ above the bench on which the front legs were resting. If the rat did not significantly alter its body posture within $30 \mathrm{sec}$, it was considered to be cataleptic.

Tissue preparation. Rats were anesthetized with Avertin (10 ml/kg, i.p.) and perfused transcardially with $200 \mathrm{ml}$ of ice-cold heparinized (500 U) PBS, followed by $300 \mathrm{ml}$ of ice-cold paraformaldehyde $(2 \%$ in PBS). The flow rate of perfusion was $25 \mathrm{ml} / \mathrm{min}$. The brains were dissected out of the skull and post-fixed overnight in $2 \%$ paraformaldehyde and then cryoprotected in 30\% sucrose solution for $2 \mathrm{~d}$. Subsequently, the brains were frozen in powdered dry ice and stored at $-80^{\circ} \mathrm{C}$ until they were processed for histochemical and immunocytochemical studies. Coronal sections ( $30 \mu \mathrm{m}$ thick) were cut with a cryostat (Leica, Milton-Keynes, UK).

Histochemical staining. Sections for cresyl violet staining were mounted onto gelatin-coated slides and stained using a $1 \%$ solution of cresyl violet acetate (Sigma). NADPH diaphorase staining was performed on freefloating cryostat sections by incubation for $60 \mathrm{~min}$ in the dark at $37^{\circ} \mathrm{C}$ in a reaction mixture containing $50 \mathrm{~mm}$ PBS, $5 \mathrm{~mm}$ magnesium chloride, 2 $\mathrm{mg} / \mathrm{ml} \mathrm{NADPH}$ (reduced form; Sigma), and $1 \mathrm{mg} / \mathrm{ml}$ nitroblue tetrazolium (Sigma).

Immunocytochemistry. Nonspecific binding was blocked by incubating free-floating coronal sections in blocking solution (3\% normal deer serum in PBS containing $0.2 \%$ Triton X-100) with $0.02 \%$ sodium azide at $4^{\circ} \mathrm{C}$ overnight. Sections were then incubated in either polyclonal rabbit antisera or monoclonal mouse antibodies. The antisera/antibodies used were polyclonal rabbit antisera raised against either purified tyrosine hydroxylase (TH; Affiniti, Exeter, UK) or purified glial fibrillary acidic protein (GFAP; Sigma) and a monoclonal mouse antibody raised against the microglial cell marker cluster of differentiation 11b (CD11b; Serotec, Oxford, UK). The sections were incubated for $7 \mathrm{~d}$ at $4^{\circ} \mathrm{C}$ in blocking solution, with $0.02 \%$ sodium azide and primary antisera/antibodies diluted to a concentration of 1:1000 for CD11b, 1:2000 for TH, and 1:5000 for GFAP. Then the sections were washed five times, for $5 \mathrm{~min}$ each, in wash solution (PBS containing $0.02 \%$ Triton X-100) and incubated at $4^{\circ} \mathrm{C}$ overnight in a horseradish peroxidase-labeled secondary antibody (1: 1000; Vector Laboratories, Peterborough, UK) raised against the host animal of the primary antibody in blocking solution without azide. Then the sections were washed five times, for $5 \mathrm{~min}$ each, with wash solution and developed with $3,3^{\prime}$-diaminobenzidine $(0.5 \mathrm{mg} / \mathrm{ml}$; Sigma $)$ in $50 \mathrm{~mm}$ Tris buffer, $\mathrm{pH} 7.6$, containing $0.009 \%$ hydrogen peroxide.

Lesion volume measurement and cell counting. Cresyl violet-stained sections were analyzed for total neuronal counts. Cells within lesions on both sides of the brain were measured. Six fields $\left(300 \mu \mathrm{m}^{2}\right.$ each, two from each of three sections) from all five animals in each group were counted to compare the survival of neurons within striatal lesions induced by 3-NP and methamphetamine with the survival of those induced by 3-NP and saline. Lesions were mapped by using camera lucida drawings so that equivalent striatal areas could be counted from saline-treated control animals. The whole of the lesion area or its equivalent area was used for NADPH diaphorase-positive neuron counts.

The volume of the 3-NP-induced striatal lesions was measured from NADPH diaphorase-stained sections by image analysis software (Q500, Leica). The striatal lesion was taken as the area of loss of NADPH diaphorase staining. (The area of loss of NADPH diaphorase staining corresponded to the area of neuronal loss, as defined by cresyl violet staining, but had a better defined edge for analysis purposes.) At least four serial sections were measured for each lesion. The lesion volume was estimated by the following formula: Volume $=d\left(a_{1}+a_{2}+a_{3}+\ldots\right)$, where $d=$ distance (in $\mathrm{mm}$ ) between serial sections and $a_{1}, a_{2}, a_{3} \ldots=$ areas $\left(\mathrm{mm}^{2}\right)$ of the lesion for individual serial sections.

In 6-OHDA-lesioned animals the volume of the 3-NP-induced striatal lesion on the 6-OHDA-lesioned (left) side of the brain was expressed as a percentage of the volume of the striatal lesion on the intact (right) side.

Counts of dopamine neurons were generated from six sections at the level of the substantia nigra, which had been stained for TH immunoreactivity. The number of TH-positive neurons surviving in the substantia nigra pars compacta $(\mathrm{SNpc})$ or ventral tegmental area (VTA) on the 6-OHDA-lesioned side was expressed as a percentage of the number of SNpc or VTA neurons on the intact side.

Statistics. The significance of numerical data was determined by a one-way ANOVA, followed by Newman-Keuls post hoc test to examine differences between treatment groups. Population data were analyzed either with Fisher's exact test, for $2 \times 2$ contingency tables, or with the $\chi^{2}$ test for larger contingency tables. A paired Student's $t$ test was used to examine the volume relationship between the left and right striatal lesions of 3-NP-treated rats. Linear regression analysis was used to examine the correlation between dopaminergic neuronal survival and striatal lesion volume. All statistical calculations were performed with the statistical program Prism (GraphPad Software, San Diego, CA). 


\begin{tabular}{|c|c|c|c|c|}
\hline \multirow{2}{*}{$\begin{array}{l}\text { Chronic/acute treatment (time } \\
\text { after last chronic injection) }\end{array}$} & \multicolumn{3}{|c|}{ Behavioral changes (Number of rats displaying behavior/Total number of rats) } & \multirow{2}{*}{$\begin{array}{l}\text { Number of rats } \\
\text { with lesions }\end{array}$} \\
\hline & Hyperactivity/stereotypy & Wobbly gait & Splayed hind legs & \\
\hline Saline/Meth (4 hr) & $4 / 4$ & $0 / 4$ & $0 / 4$ & $0 / 4$ \\
\hline 3-NP/Saline (4 hr) & $0 / 19$ & $0 / 19$ & $0 / 19$ & $2 / 19$ \\
\hline 3-NP/Meth (4 hr) & $14 / 14$ & $14 / 14$ & $10 / 14$ & $14 / 14^{a}$ \\
\hline 3-NP/Meth (24 hr) & $8 / 8$ & $5 / 8$ & $2 / 8$ & $3 / 8^{b}$ \\
\hline
\end{tabular}

$a_{p}<0.0001$ compared with $3-\mathrm{NP} /$ Saline $(4 \mathrm{hr}) ;{ }^{b} p=0.136$ compared with $3-\mathrm{NP} /$ Saline $(4 \mathrm{hr})$.

\section{RESULTS}

\section{Behavioral effects of low-dose chronic 3-NP}

None of the rats treated with $12 \mathrm{mg} / \mathrm{kg} 3-\mathrm{NP}$ for $7 \mathrm{~d}$ showed the pronounced behavioral signs of $3-\mathrm{NP}$ toxicity associated with lesion formation (see below). This is consistent with previous findings that lesion formation in rats treated with low doses of $3-\mathrm{NP}$ is infrequent and very variable, with only 1 of 10 rats likely to have a lesion after 7 d (Beal et al., 1993; Wüllner et al., 1994; D. Reynolds and A. J. Morton, unpublished observations).

\section{Behavioral effects of acute methamphetamine}

A few minutes after methamphetamine was administered to saline-treated control rats, all displayed a marked increase in locomotor and exploratory behavior (Table 1). This period of hyperactivity lasted $\sim 30$ min before being replaced gradually by stereotypy. Stereotypic sniffing and head bobbing predominated for the next 2-3 hr, although locomotion was not abolished completely. Stereotypy began to decline $\sim 3 \mathrm{hr}$ after the methamphetamine injection, and movement returned to preinjection levels after 4-5 hr. No gait or postural changes were observed in these animals, nor was piloerection observed.

Pretreatment of rats with 3-NP for 1 week had no effect on initial behavioral responses to methamphetamine administered 4 hr after the final 3-NP injection, and within a few minutes all rats displayed an increase in locomotor and exploratory activity that was very similar to that of the saline-treated control rats. However, marked differences in the behavior of the two groups rapidly became apparent, with all of the 3-NP-treated rats developing a wobbly, uncoordinated gait within $20 \mathrm{~min}$ of the methamphetamine injection. In 4 of the 14 animals the gait remained wobbly for several hours and then gradually returned to normal. However, hind limb movement of the remaining 10 animals became progressively more uncoordinated, resulting first in sideways falling during walking and finally in hind limb recumbency with the back legs splayed out from the body. Despite severe coordination problems, these animals were able to move, but they were propelled forward mainly by the front legs with little contribution from the hind legs, which performed paddle-like movements. Hind limb recumbency persisted for $\sim 1$ hr before a gradual recovery of hind limb function was observed. The majority of rats displaying hind recumbency also developed piloerection that lasted for the duration of the observation period.

The eight rats to whom methamphetamine $(5 \mathrm{mg} / \mathrm{kg})$ was administered $24 \mathrm{hr}$ after the last 3-NP injection displayed a similar, but less severe, set of behavioral changes as compared with those given methamphetamine $4 \mathrm{hr}$ after the final 3-NP injection. All rats displayed hyperactivity that gradually gave way to stereotypy after $\sim 30 \mathrm{~min}$. However, only five of eight developed a wobbly, uncoordinated gait, and of those only two animals progressed to hind limb recumbency.
The day after acute methamphetamine treatment, all rats appeared behaviorally normal. A slight decrease in body weight was recorded, but this weight was regained by the next day.

\section{Methamphetamine increases frequency of 3-NP lesions}

Histological examination of the brains of rats treated with methamphetamine $4 \mathrm{hr}$ after the last 3-NP injection showed that all 14 had bilateral striatal lesions (Table 1; Fig. 1). By comparison, only 2 of the 19 brains from rats treated with $3-\mathrm{NP}$ and saline displayed striatal lesions, and none of the animals that received methamphetamine alone displayed lesions. Thus, chronic pretreatment of rats with a low dose of 3-NP dramatically increased the striatal toxicity of a small, normally nontoxic, dose of methamphetamine $(p<0.0001)$. The increased toxicity of methamphetamine critically depended on the time interval between the final 3-NP injection and the methamphetamine injection, because delaying methamphetamine treatment until $24 \mathrm{hr}$ after the last 3-NP injection reduced the number of rats displaying striatal lesions to a level not statistically different from the frequency of lesions induced by $3-\mathrm{NP}$ and saline (Table $1 ; p=0.136$ ).

\section{Extrastriatal brain regions are not damaged after 3-NP/methamphetamine treatment}

Lesions induced by chronic 3-NP are primarily striatal. However, extrastriatal damage to the thalamus and hippocampus has been reported in some animals after prolonged treatment with 3-NP (Hamilton and Gould, 1987; Beal et al., 1993; Allen et al., 1994; Miller and Zaborszky, 1997). Here, neuronal damage caused by the acute administration of methamphetamine to 3-NP-treated rats was restricted to the striatum, and no damage was seen in the extrastriatal regions of any rat after $3-\mathrm{NP} /$ methamphetamine treatment.

\section{Characterization of neuronal loss induced by 3-NP/methamphetamine treatment}

The histopathology of the lesions induced by 3-NP/methamphetamine was similar, but not identical, to that of lesions induced by 3-NP treatment alone. In both cases, bilateral lesions were found in the dorsolateral striatum and became more ventrolateral at the caudal extremes of the lesion (Fig. 1a,b). However, the lesions induced by $3-\mathrm{NP} / \mathrm{methamphetamine}$ were generally smaller $\left[4.16 \pm 0.42 \mathrm{~mm}^{3}\right.$ for the $4 \mathrm{hr}$ group $(n=14)$ and $3.82 \pm 0.64$ $\mathrm{mm}^{3}$ for the $24 \mathrm{hr}$ group $\left.(n=3)\right]$ than those induced by $3-\mathrm{NP}$ alone $\left[7.64 \pm 0.63 \mathrm{~mm}^{3}(n=2)\right]$, and there was a different pattern of neuronal loss within each type of lesion.

The loss of NADPH diaphorase neuropil staining was used to delineate the borders of the lesions as well as to determine the survival of NADPH diaphorase neurons. In unlesioned brain, NADPH diaphorase staining showed strong neuropil staining throughout the striatum, with intensely stained NADPH diapho- 

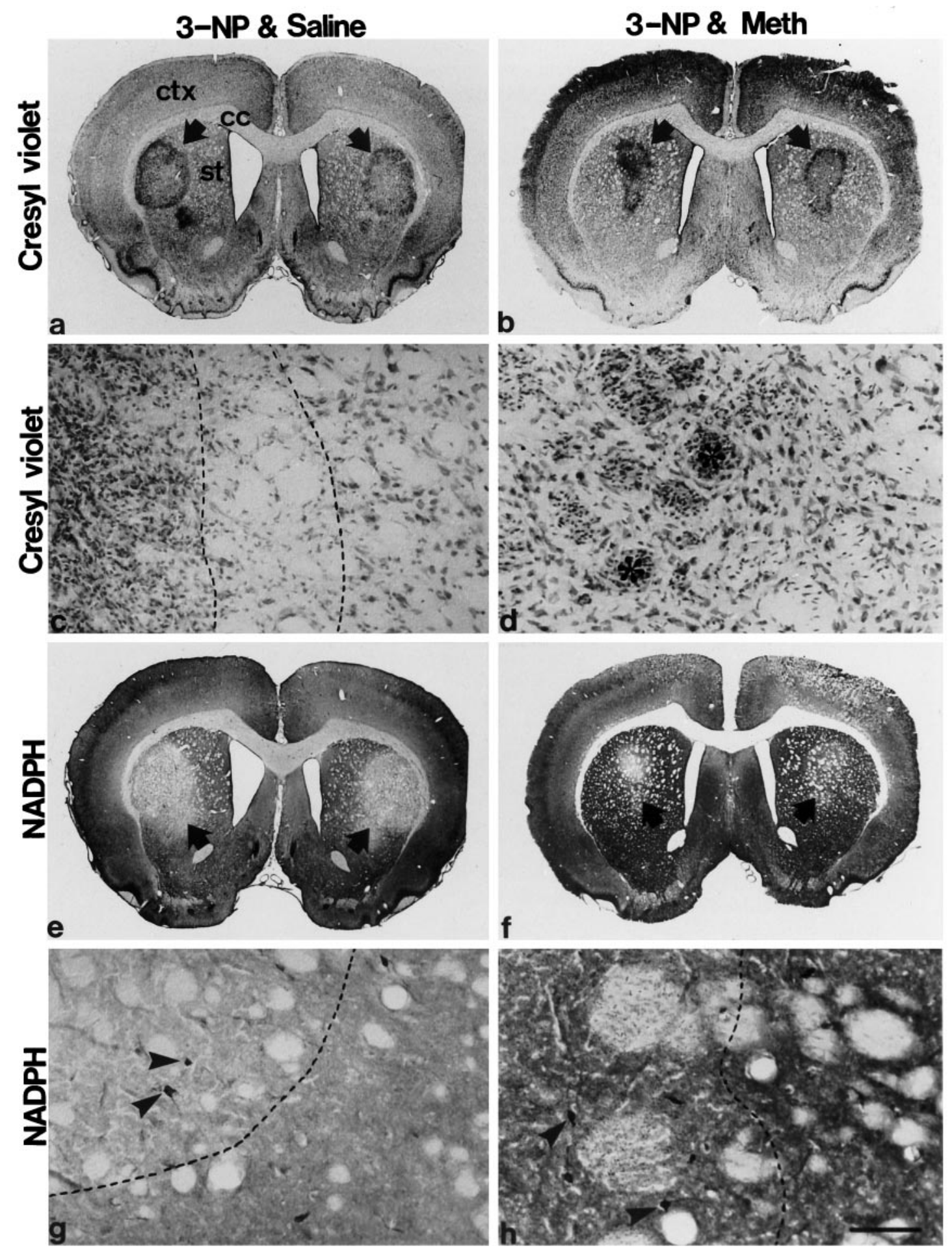

Figure 1. Histological appearance of spontaneous (3-NP\& Saline) and methamphetamine-induced (3-NP \& Meth) lesions in rat brain. Parallel coronal sections of rat brain were stained for cresyl violet $(a-d)$ or NADPH diaphorase activity $(e-h)$. Spontaneously induced lesions $($ arrows, $a$, $e)$ displayed reactive gliosis, which was especially dense around the edge of the lesions ( $a$ and left-hand zone in $c$ ). Limited neuronal survival and diffuse gliosis were seen in the penumbral region of the lesion (middle zone, $c$ ). Methamphetamine-induced lesions (arrows, $b, f$ ) displayed gliosis, which was localized predominantly over the fiber bundles at the edges of the lesion (asterisks, $d$ ). In spontaneous 3-NP lesions, NADPH diaphorase-positive neuropil staining was markedly reduced in the center of the lesion, and no NADPH diaphorase-positive neurons were seen in this region. In the penumbral region (upper left zone, $g$ ) there was also reduced neuropil staining, although some surviving NADPH diaphorase-positive neurons were observed (arrowheads, $g$ ). In contrast, in 3-NP/methamphetamine-induced lesions there was stronger NADPH diaphorase neuropil staining (arrows, $f$ ), with greater sparing of positively stained neurons (arrowheads, $h$ ). Scale bars: $a, b, e, f, 2 \mathrm{~mm} ; c, d, g, h, 50 \mu \mathrm{m}$. ctx, Cortex; $c c$, corpus callosum; st, striatum. 


\begin{tabular}{|c|c|c|}
\hline Treatment & $\begin{array}{l}\text { Total number of neurons } \\
\text { (per } \mathrm{mm}^{2}, n=5 \text { rats) }\end{array}$ & $\begin{array}{l}\text { Number of NADPH neurons } \\
\text { (per } \mathrm{mm}^{2} ; n=5 \text { rats) }\end{array}$ \\
\hline Saline & $1092 \pm 9$ & $8.85 \pm 1.19$ \\
\hline 3-NP and methamphetamine & $634 \pm 90^{a}$ & $3.93 \pm 0.71^{b}$ \\
\hline 3-NP alone & $4.80 \pm 2.44^{c}$ & $0.079 \pm 0.061^{d}$ \\
\hline
\end{tabular}

${ }^{a, b} p<0.05$ compared with saline; ${ }^{c, d} p<0.001$ compared with saline.

rase interneurons scattered throughout the striatal neuropil. In rats with 3-NP lesions, NADPH diaphorase staining showed well circumscribed areas of very pale staining (Fig. 1e), which corresponded to the area of neuronal loss in adjacent sections stained with cresyl violet (compare Fig. 1a). Within these lesions there was a core region in which there was an increase in gliosis and in which neuronal loss was virtually complete (Fig. 1a,c, left zone), surrounded by a penumbral region in which NADPH diaphorase staining was reduced but in which the loss of neurons was less pronounced (Fig. 1c, middle zone). These findings are similar to those observed by others (Beal et al., 1993; Bossi et al., 1993).

In $3-\mathrm{NP} /$ methamphetamine-treated rats, the lesion area was defined by an increase in gliosis (Fig. 1b,d) and a loss of NADPH diaphorase staining (Fig. 1f). However, within these lesions there was no obvious core/penumbral division (Figure $1 d$ ), and neuronal loss appeared uniform throughout the lesion area. This observation was confirmed by neuron counting, and quantification of total neuronal loss showed that within the central region of the 3-NP/methamphetamine lesions neuronal loss was less severe ( $40 \%$ of total number of neurons) than was seen in the corresponding region of lesions from rats treated with $3-\mathrm{NP}$ alone (>95\% loss; $p<0.001)$ (Table 2).

The sparing of striatal NADPH diaphorase-positive interneurons is a hallmark of the striatal damage in HD and often is used as a histopathological measure of the usefulness of animal models of HD. In lesions induced by 3-NP alone, few NADPH diaphorase-positive neurons were found within the core region, although there was limited sparing of these neurons in the penumbral region (Fig. 1g, upper left). This is consistent with the findings of others (Beal et al., 1993; Bossi et al., 1993). In contrast, within the $3-\mathrm{NP} /$ methamphetamine-induced lesion $45 \%$ of the NADPH diaphorase neurons were spared within the lesion area (Table 2; Fig. 1h). This suggests that, although the lesions were similar in many ways, neurotoxic damage seen after $3-\mathrm{NP} / \mathrm{meth}-$ amphetamine treatment is less severe than that seen with 3-NP alone.

\section{Glial reactions associated with methamphetamine and 3-NP-induced lesions}

There was a highly consistent astroglial reaction associated with both 3-NP-induced lesions and 3-NP and methamphetamineinduced lesions. All lesions, whether induced by 3-NP/methamphetamine or 3-NP alone showed a pronounced astrogliosis in the penumbra of the lesions (Fig. $2 a-d$ ). Although there was astrogliosis within the core of both types of lesion, this was less pronounced than in the penumbral regions. No astrogliosis was observed in the striata of rats treated with saline and methamphetamine (data not shown).

Microglia were observed in all lesions, although the distribution of the microglial reaction was very different in the two types of lesion (Fig. $2 e-h$ ). Lesions induced by $3-\mathrm{NP}$ alone displayed intense immunoreactivity for microglial markers in neuropil and fiber bundles throughout the whole lesion (Fig. $2 e, g$ ), whereas the microglial reaction in lesions induced by $3-\mathrm{NP} /$ methamphetamine was much less severe and was associated primarily with fiber bundles (Fig. 2f,h).

\section{The effect of dopamine antagonists on 3-NP/methamphetamine-induced behavior}

The role of dopamine receptors in lesion formation was examined by the use of selective dopamine receptor antagonists, with SCH23390 and sulpiride used to block $\mathrm{D}_{1}$ and $\mathrm{D}_{2}$ receptors, respectively. Pilot studies were conducted to determine appropriate doses of the antagonists. The dose of each antagonist for these experiments was chosen so that (1) the dose was within the range at which the drug action is selective for $\mathrm{D}_{1}$ or $\mathrm{D}_{2}$ type dopamine receptors (Mailman et al., 1997), and (2) dopamine-mediated behaviors (e.g., hypoactivity and catalepsy) were induced in drugnaive control animals by a single dose of the antagonist.

Pretreatment of the saline-treated control animals with either sulpiride or SCH23390 resulted in a marked reduction in spontaneous movement in all animals (Table 3). Both drugs also caused catalepsy in most animals in the experimental group (Table 3). The administration of sulpiride and SCH23390 together resulted in hypoactivity and induced catalepsy in 8 of 10 rats.

The pretreatment of rats with sulpiride did not prevent methamphetamine-induced activity but prevented the development of stereotypical movements in more than one-half of the animals (Table 3). In contrast, SCH23390 had little or no effect on either methamphetamine-induced hyperactivity or the development of stereotypy. Seven 3-NP rats pretreated with sulpiride and four rats pretreated with $\mathrm{SCH} 23390$ developed a wobbly gait $\sim 20$ min after methamphetamine treatment; three animals in each group then went on to display hind limb recumbency. When both antagonists were administered together, methamphetamineinduced activity and stereotypy were greatly reduced. Although 4 of 10 rats pretreated with both antagonists developed a wobbly gait, only one of these became recumbent.

\section{Effect of dopamine antagonists on methamphetamine/} 3-NP-induced lesion formation

Blocking $\mathrm{D}_{2}$ receptors with sulpiride did not prevent 3-NP/ methamphetamine-induced lesions. Fewer lesions were induced in rats pretreated with the $\mathrm{D}_{1}$ antagonist SCH23390, and when both antagonists were administered simultaneously, the number of rats presenting with lesions was greatly reduced. These data suggest that, although $\mathrm{D}_{1}$ receptor activity plays a part in 3-NPinduced lesion formation, both receptor subtypes are important for the mediating effects of dopamine.

Histopathologically, there was no difference between the neuropathological profiles of lesions induced by 3-NP/methamphetamine in the presence of dopamine receptor antagonists and 

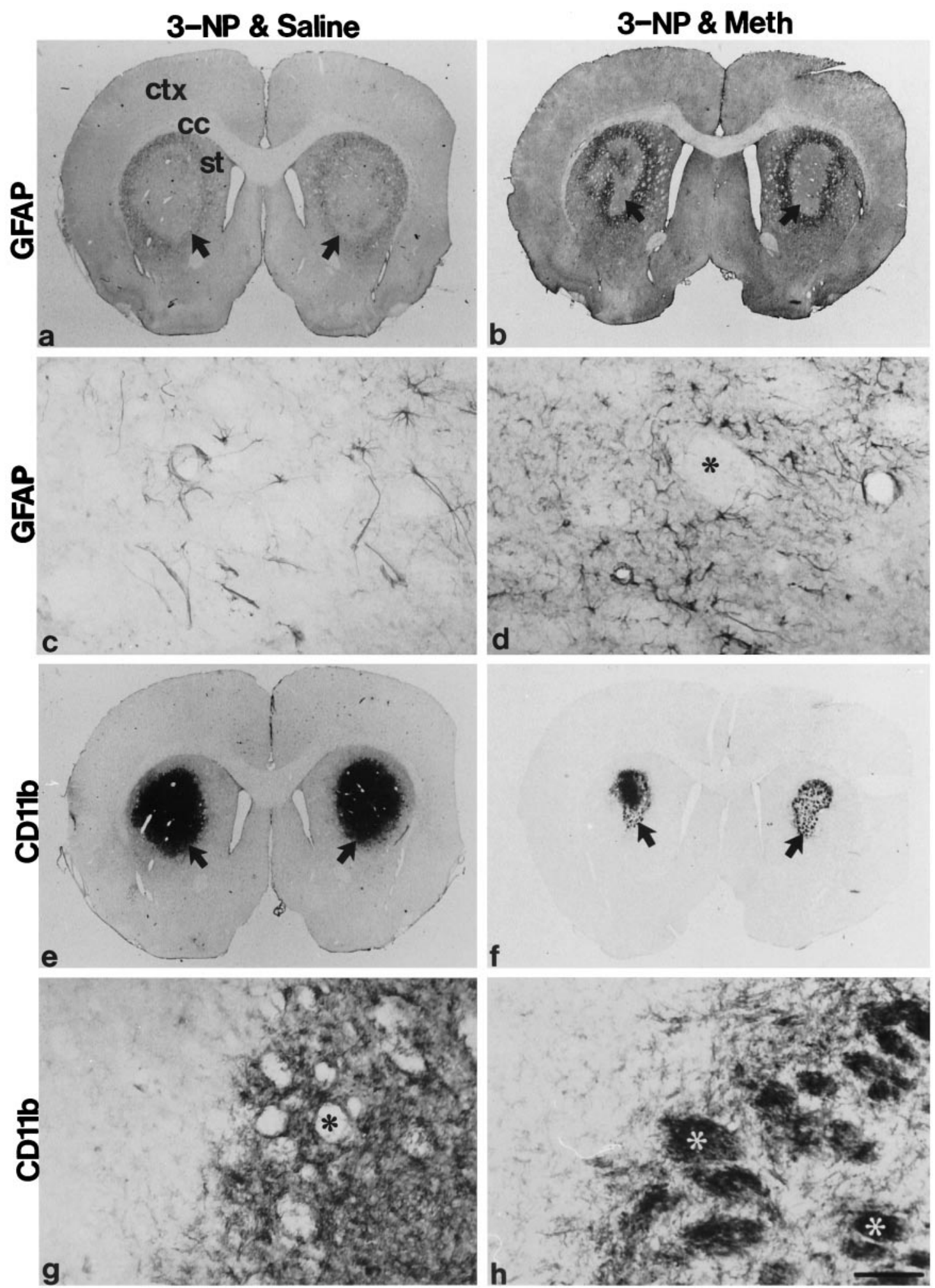

Figure 2. Glial and microglial immunoreactivity in spontaneous (3-NP\& Saline) and methamphetamine-induced (3-NP \& Meth) lesions in rat brain. Parallel coronal rat brain sections were stained for GFAP $(a-d)$ or CD11b $(e-h)$ immunoreactivity. Lesions induced by 3 -NP and saline $(a, c, e$, $g)$ show the typical pattern of gliosis associated with 3-NP lesions. Increased astrogliosis was seen in the penumbral region of the lesions $(a, c)$, whereas microgliosis was very dense throughout the lesion $(e, g)$. Methamphetamine-induced lesions also displayed gliosis in the penumbral region $(b, d)$; this was not associated with fiber bundles (asterisk, $d$ ). The extent of microgliosis associated with the neuropil varied in lesions of different animals (compare left and right lesions, $f$ ) but was generally less intense than that seen in spontaneous lesions. Microglial staining often was strongly associated with fiber bundles (asterisks, $h$ ). Scale bars: $a, b, e, f, 2 \mathrm{~mm} ; c, d, g, h, 100 \mu \mathrm{m}$. ctx, Cortex; $c c$, corpus callosum; st, striatum. 
Table 3. Effect of dopamine antagonists on methamphetamine-induced changes

Behavioral changes (Number of rats displaying behavior/Total number of rats)

\begin{tabular}{|c|c|c|c|c|c|}
\hline \multirow[b]{2}{*}{ Treatment } & \multicolumn{4}{|c|}{ ats } & \multirow{2}{*}{$\begin{array}{l}\text { Number of rats } \\
\text { with lesions }\end{array}$} \\
\hline & Hyperactivity & Stereotype & Wobbly gait & Splayed hind legs & \\
\hline Saline & $14 / 14$ & $14 / 14$ & $14 / 14$ & $10 / 14$ & $14 / 14$ \\
\hline Sulpiride & $7 / 10$ & $4 / 10$ & $7 / 10$ & $3 / 10$ & $9 / 10$ \\
\hline SCH23390 & $9 / 10$ & $7 / 10$ & $4 / 10$ & $3 / 10$ & $6 / 10^{a}$ \\
\hline SCH23390 + sulpiride & $3 / 10$ & $1 / 10$ & $4 / 10$ & $1 / 10$ & $2 / 10^{b}$ \\
\hline
\end{tabular}

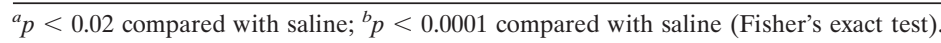

those induced by $3-\mathrm{NP} /$ methamphetamine alone (data not shown).

\section{The effect of 6-OHDA lesions on 3-NP-induced behavioral changes}

To determine the effect of lowered dopamine levels on 3-NP lesion formation, we performed a unilateral 6-OHDA lesion of the median forebrain bundle $7 \mathrm{~d}$ before rats began their 3-NP treatment. Because 3-NP was administered systemically, the unlesioned contralateral striatum served as the control for 3-NP lesion formation in individual rats.

Because lesion formation induced by the use of constant low doses of 3-NP $(12 \mathrm{mg} / \mathrm{kg})$ is unpredictable, in these experiments a more severe 3-NP treatment was used, with stepwise increases in the dose of 3-NP. With the stepwise protocol the characteristic behaviors consistent with 3-NP intoxication were observed after an average of 7 or $8 \mathrm{~d}$. At 1-2 hr after its final 3-NP injection the rat became ataxic, sitting in hunched position, and often displayed marked piloerection. The hind limbs usually were splayed out to either side of the body, and their movement was uncoordinated during locomotion. Rats displaying symptoms of intoxication received no further 3-NP injections and recovered functionally over the next few days.

The behavioral changes associated with 3-NP intoxication in 6-OHDA-lesioned rats were very similar to those seen in intact rats. The only difference was that some 6-OHDA-lesioned rats (4 of 10) displayed a small degree of anticlockwise rotational movement when placed in a novel environment.

\section{6-OHDA lesions protect against 3-NP-induced striatal lesions}

All intact rats treated with 3-NP developed bilateral striatal lesions. Although the lesion volume varied somewhat among animals $\left(9.41 \pm 2.76 \mathrm{~mm}^{3}\right)$, there was no significant difference between the left and right striatal lesions of a given animal ( $p=$ 0.442 , paired $t$ test). In contrast, in 6-OHDA-lesioned rats, removal of the dopaminergic input to the striatum provided significant protection against 3-NP-induced striatal toxicity. In two of the rats this protection was complete, and no lesion was seen on the dopamine-denervated side (Fig. $3 a-e$ ). The remaining nine animals had bilateral lesions, but in all rats the lesion in the dopamine-denervated striatum was significantly smaller than the lesion in the intact striatum $(p<0.0002$, paired $t$ test; denervated side $=2.04 \pm 0.71 \mathrm{~mm}^{3}$ and intact side $\left.=4.85 \pm 0.97 \mathrm{~mm}^{3}\right)$.

The histopathological characteristics of the striatal lesions in 6-OHDA-lesioned rats were very similar to those of lesions induced in intact rats, with neuronal loss and pronounced CD11b immunoreactivity throughout the region of the lesion and increased reactive gliosis in the penumbral region (Fig. 3a-d). Although the lesions in the intact contralateral striatum were slightly smaller than those seen in intact rats treated with 3-NP, this difference did not reach statistical significance.

\section{Striatal lesion volume correlates with the extent of nigrostriatal dopamine input}

TH immunocytochemistry confirmed the expected loss of dopaminergic neurons from the lesioned side of the brain in the 6-OHDA-lesioned animals (Fig. 3e,f). The extent of loss varied among animals, with loss of dopaminergic neurons from both the $\mathrm{SNpc}$ as well as the VTA. There was a strong correlation between the size of the striatal lesions and the extent of dopaminergic innervation from the SNpc $\left(r^{2}=0.66 ; p<0.002\right.$, linear regression) (Fig. 4), but not the VTA $\left(r^{2}=0.03\right)$.

There was no effect on the total number of TH-positive neurons in the SN/VTA after 3-NP treatment or after 3-NP/methamphetamine treatment [TH cell counts in the SN/VTA were saline $219 \pm 20 ; 3-\mathrm{NP}$ alone, $234 \pm 15 ; 3-\mathrm{NP} / \mathrm{methamphetamine}$, $231 \pm 11$. Numbers are the mean number of TH-positive cells per section, five sections per animal, and five animals for each group (all sections at comparable levels)].

\section{DISCUSSION}

\section{Current theories do not account fully for the neurotoxic action of 3-NP}

One of the strengths of the energy impairment/excitotoxicity hypothesis is that it proposes a means whereby striatal damage can occur without the elevation of striatal glutamate levels usually associated with excitotoxicity. This is particularly important because glutamate levels do not appear to be increased in HD (Nicoli et al., 1993). However, the main weakness of this hypothesis is that succinate dehydrogenase ( $\mathrm{SDH}$ ) activity in all neurons in the brain is affected similarly by $3-\mathrm{NP}$ (Gould et al., 1985; Brouillet et al., 1998). Thus one would expect that other neurons that are targets for glutamate input (e.g., CA1 neurons in the hippocampus and Purkinje cells in the cerebellum) also would be vulnerable to endogenous glutamate in 3-NP-intoxicated animals. This does not appear to be the case, and although lesions are seen occasionally in the hippocampus, extrastriatal regions do not appear to be vulnerable to 3-NP (Bossi et al., 1993; Wüllner et al., 1994; Fu et al., 1995a; Nishino et al., 1995; Shimano et al., 1995). Thus the current hypothesis does not account fully for the striatal selectivity of 3-NP neurotoxicity. It seems likely that another factor must be important for the induction of 3-NP lesions; we propose that this factor is dopamine.

\section{Dopamine action underlies the development of 3-NP lesions}

We used methamphetamine to increase dopamine levels in vivo. The increase in dopamine after methamphetamine is well described (Schmidt et al., 1985; O’Dell et al., 1993) (for other 

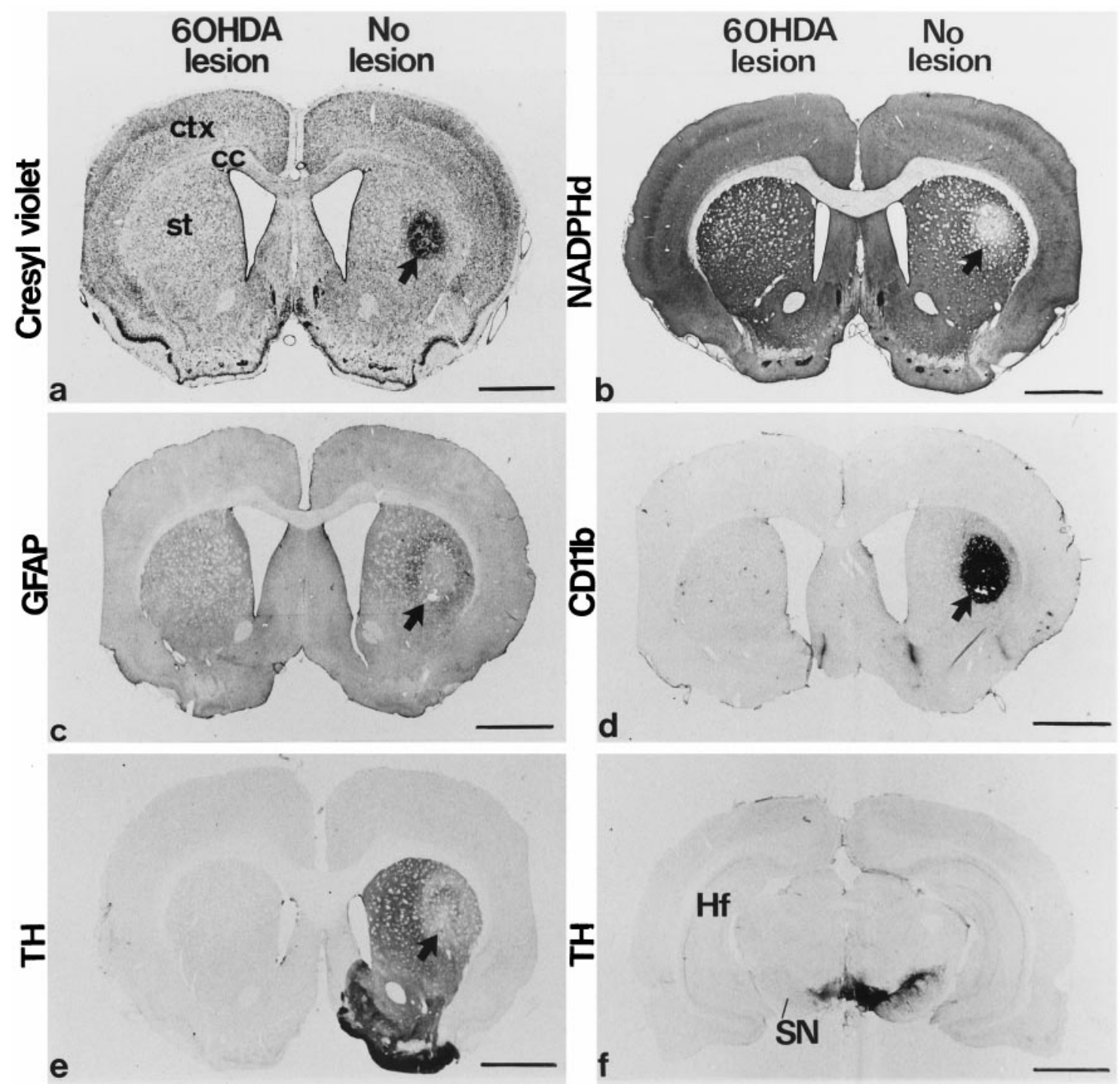

Figure 3. The effect of 6-OHDA lesions on 3-NP-induced striatal lesion formation. A striatal 3-NP lesion is observed only on the side with the intact dopamine input (arrows, right side). Cresyl violet $(a)$, NADPH $(b)$, GFAP $(c)$, and CD11b $(d)$ staining of the striatal lesion is very similar to that seen in rats with bilateral striatal 3-NP lesions (compare with Fig. 1). There is no striatal pathology visible on the lesioned side. TH staining $(e, f)$ revealed a marked loss of dopaminergic neurons from the SNpc $(f)$ on the 6-OHDA-lesioned side of the brain and complete loss of staining in the ipsilateral striatum (e). Scale bar, $2 \mathrm{~mm}$. ctx, Cortex; $c c$, corpus callosum; st, striatum; $H f$, hippocampus; $S N$, substantia nigra.

references, see Seiden and Ricuarte, 1987; Gibb et al., 1990). Although we did not measure striatal dopamine levels directly, blocking dopamine receptors is known to reduce methamphetamine-induced rises in dopamine (O'Dell et al., 1993) and in this study prevented the formation of methamphetamine-induced lesions in 3-NP-treated rats (Table 3).

The increase in lesion frequency seen after methamphetamine was very interesting, because although methamphetamine and amphetamine are both toxic, large or repeated doses of these drugs usually are required to cause damage in normal rats (Ellison et al., 1978; O'Dell et al., 1993, 1994; Bowyer et al., 1994; Finnegan and Taraska, 1996). The dose we chose is used to test rotational behavior (Ungerstedt and Arbuthnott, 1970; Dunnett et al., 1987, 1988) and does not cause neuronal or terminal damage (Ungerstedt and Arbuthnott, 1970). Thus it appears that 3-NP increased the vulnerability of striatal neurons to methamphetamine. The toxicity of methamphetamine was more pro- nounced when administered $4 \mathrm{hr}$, rather than $24 \mathrm{hr}$, after the last 3-NP injection. This supports the suggestion that the increased vulnerability is a consequence of energy impairment rather than a change in the efficacy of methamphetamine. [Several studies have shown that SDH inhibition is maintained for at least $24 \mathrm{hr}$ after 3-NP treatment (Palfi et al., 1996; Nony et al., 1997; Brouillet et al., 1998), but partial recovery of SDH activity by de novo synthesis of the enzyme would be expected during this time. Hence, increased SDH activity during the recovery period may restore energy levels sufficiently to prevent methamphetamine toxicity.]

\section{Development of spontaneous 3-NP lesions depends on an intact nigrostriatal dopamine input}

Because the appearance of spontaneous lesions after 3-NP treatment is unpredictable, it was not practical to use dopamine receptor antagonists to block their development. Instead, we examined the role of dopamine by removing the nigrostriatal 


\section{SNpc}

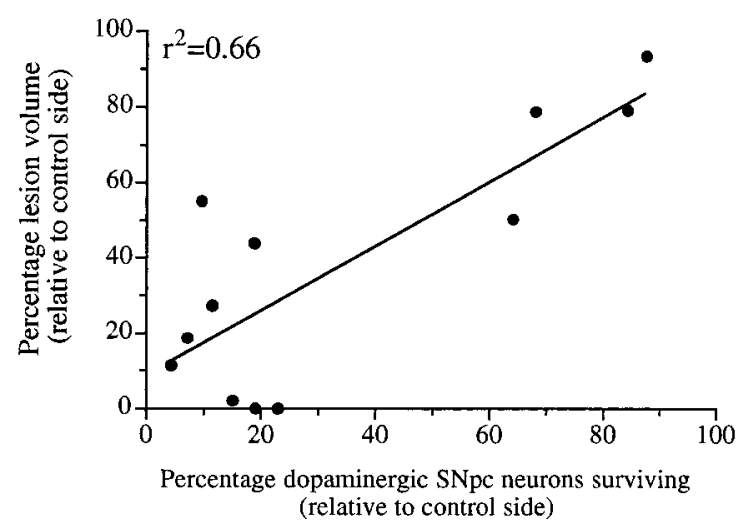

VTA

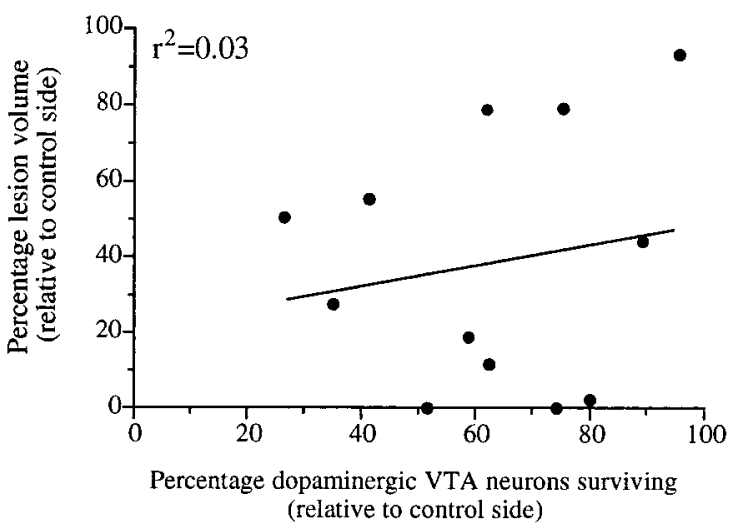

Figure 4. Correlation of relative striatal lesion volume with the number of SNpc or VTA dopaminergic neurons surviving on the 6-OHDA-lesioned side. There was a strong correlation between lesion volume and the number of dopamine neurons in the SNpc $\left(r^{2}=0.662 ; p<0.002\right)$, but not in the VTA $\left(r^{2}=0.03\right)$. The lesion volume on the denervated side was expressed as a percentage of that seen on the intact side. The number of dopaminergic neurons on the lesioned side was expressed as a percentage of the number of those on the contralateral side.

input to one striatum, allowing the intact side to serve as the control. Complete removal of dopamine input prevented the formation of 3-NP lesions in the denervated striatum while having no effect on the formation of the lesion in the contralateral striatum. In animals in which partial 6-OHDA lesions were seen, there was a strong correlation between the number of dopamine neurons in the SNpc and the size of the 3-NP-induced striatal lesion. In contrast, there was a poor correlation between lesion size and dopaminergic neuron survival in the VTA. This is consistent with the idea that dopamine increases the vulnerability of striatal neurons to 3-NP, because the neurons surviving in the VTA were found in the medial areas that project to cortex rather than to striatum (Fallon and Loughlin, 1995).

\section{Mechanism of action of dopamine in striatal 3-NP toxicity}

Dopamine plays a central role in methamphetamine toxicity and is likely to be similarly important in the development of the 3-NP/methamphetamine lesions. Methamphetamine toxicity is mediated via a number of mechanisms, both direct [via the auto-oxidation of dopamine and methamphetamine to reactive oxygen species (ROS) (Breese and Traylor, 1970; Cohen and Heikkila, 1974; Graham, 1978; Seiden and Vosmer, 1984; Giovanni et al., 1995)] and indirect [via excitotoxic routes, because increased extracellular dopamine potentiates glutamate release (Nash and Yamamoto, 1993; Hu and White, 1997) and NMDA receptor antagonists block methamphetamine toxicity (Sonsalla et al., 1989, 1991; Green et al., 1992; Baldwin et al., 1993; Finnegan and Taraska, 1996) or via interactions with NO (Sheng et al., 1996; Ali and Itzhak, 1998)]. Interestingly, similar hypotheses have been proposed to account for the neurotoxicity of 3-NP. For example, it has been suggested that ROS generation/NO are important (Fu et al., 1995b; Galpern et al., 1996; Schulz et al., 1996; Tsai et al., 1997), and NO synthase inhibitors (Schulz et al., 1995) and certain free radical scavengers (Nakao and Brundin, 1997) can protect against 3-NP-induced damage. Furthermore, glutamate excitotoxicity is central to the energy depletion/excitotoxicity hypothesis (Novelli et al., 1988; Simpson and Isacson, 1993). The possibility that a similar mechanism accounts for the action of both methamphetamine and 3-NP therefore is consistent with the possibility that dopamine plays an important role in 3-NP toxicity.
Although the current hypotheses aimed at explaining 3-NP toxicity in vivo do not include a role for dopamine, such a role fits very well with other data. As well as having modulatory effects on striatal glutamate release, dopamine itself can be neurotoxic (Filloux and Townsend, 1993; Ben-Shachar et al., 1995; Cheng et al., 1996; Hastings et al., 1996). Although to our knowledge striatal dopamine levels have not been measured during chronic 3-NP treatment, large changes in dopamine levels have been observed under conditions in which neurotoxic damage results, e.g., anoxia and transient ischemia (Globus et al., 1988; Slivka et al., 1988). Furthermore, endogenous dopamine exacerbates the striatal toxicity of glutamate receptor agonists (Chapman et al., 1989; Filloux and Wamsley, 1991; Garside et al., 1996). Finally, it recently has been shown in vitro that mitochondrial inhibition potentiates dopamine toxicity in striatal cultures (McLaughlin et al., 1998).

We suggest that the current energy/excitotoxic hypothesis for 3-NP toxicity should be expanded to include a role for dopamine, because the vulnerability of striatal neurons to 3-NP depends on an intact dopamine input. It seems likely that the striatal selectivity of 3-NP lesions is attributable to the striatum being a major target for both dopaminergic and glutamatergic inputs, making it the most vulnerable region in the 3-NP-intoxicated brain.

\section{A role for dopamine in 3-NP lesion formation: Implications for the treatment of HD}

Although direct evidence for an involvement of dopamine in HD pathology is sparse, there is considerable evidence suggesting that changes in the dopaminergic system occur in HD. Dopamine receptors are decreased in HD patients (Sedvall et al., 1994; Antonini et al., 1996; Weeks et al., 1996; Ginovart et al., 1997), in asymptomatic HD gene carriers (Antonini et al., 1996; Weeks et al., 1996), and in transgenic HD mice (Cha et al., 1998). The function of the decrease in dopamine receptors is not known, but one of the consequences of these changes may be an increase in dopamine release (via a decrease in presynaptic autoinhibitory $\mathrm{D}_{2}$ action). Our experiments suggest that an increase in dopamine would potentiate striatal neurotoxicity, particularly if there were an underlying energy deficit in HD. 3-NP is an irreversible inhibitor of SDH of Complex II in the mitochondrial chain, and the striatal toxicity associated with 3-NP intoxication suggests that a metabolic deficit might be important in the mechanism 
underlying neurodegeneration in HD (Ludolph et al., 1992; Erecinska and Nelson, 1994; Koroshetz et al., 1994; Tsai et al., 1997). This suggestion is supported by a growing body of evidence, including nuclear magnetic resonance studies (Jenkins et al., 1993; Antonini et al., 1996; Harms et al., 1997) and biochemical studies (Brennan et al., 1985; Butterworth et al., 1985; Parker et al., 1990; Koroshetz et al., 1993, 1997; Gu et al., 1996).

We provide evidence for a direct role of dopamine in striatal 3-NP toxicity. This may be of particular importance for understanding the early pathology of $\mathrm{HD}$, where despite ubiquitous expression of the defective HD gene and its protein product in the CNS (Sharp et al., 1995; Ferrante et al., 1997), neurodegeneration is primarily striatal. There is no treatment for HD, and although antidopaminergic therapy has been considered (Tyler et al., 1996), $\mathrm{D}_{2}$ blockers do not appear to affect the long-term progression of HD. Nevertheless, we suggest that dopamine is important in the neurodegenerative processes underlying HD and that its role in HD needs to be reevaluated, because modulation of the dopaminergic system might provide a target for therapy for this devastating disease.

\section{REFERENCES}

Ali F, Itzhak Y (1998) Effects of 7-nitroindazole, an NOS inhibitor, on methamphetamine-induced dopaminergic and serotonergic neurotoxicity in mice. Ann NY Acad Sci 844:122-130.

Allen CN, Marino JL, Meshul CK (1994) 3-Nitropropionic acid (3NPA)-induced axonal degeneration: a silver impregnation study. Neurodegeneration 3:225-233.

Antonini A, Leenders KL, Spiegel R, Meier D, Vontobel P, WeigellWeber M, Sanchez-Pernaute R, de Yébenez JG, Boesiger P, Weindl A, Maguire RP (1996) Striatal glucose metabolism and dopamine $\mathrm{D}_{2}$ receptor binding in asymptomatic gene carriers and patients with Huntington's disease. Brain 119:2085-2095.

Baldwin HA, Colado MI, Murray TK, De Souza RJ, Green AR (1993) Striatal dopamine release in vivo following neurotoxic doses of methamphetamine and effect of the neuroprotective drugs, chlormethiazole and dizocilpine. Br J Pharmacol 108:590-596.

Beal MF, Kowall NW, Ellison DW, Mazurek MF, Swartz KJ, Martin JB (1986) Replication of the neurochemical characteristics of Huntington's disease by quinolinic acid. Nature 321:168-171.

Beal MF, Brouillet E, Jenkins BG, Ferrante RJ, Kowall NW, Miller JM, Storey E, Srivastava R, Rosen BR, Hyman BT (1993) Neurochemical and histologic characterization of striatal excitotoxic lesions produced by the mitochondrial toxin 3-nitropropionic acid. J Neurosci 13:4181-4192.

Ben-Shachar D, Zuk R, Glinka Y (1995) Dopamine neurotoxicity: inhibition of mitochondrial respiration. J Neurochem 64:718-723.

Bischoff S, Heinrich M, Sonntag JM, Krauss J (1986) The $\mathrm{D}_{1}$ dopamine receptor antagonist $\mathrm{SCH} 23390$ also interacts potently with brain serotonin (5-HT2) receptors. Eur J Pharmacol 129:367-370.

Björkland A, Lindvall O (1984) Dopamine-containing systems in the CNS. In: Classical transmitters in the CNS, Pt I (Björklund A, Hökfelt T, eds), pp 55-74. Amsterdam: Elsevier.

Bossi SR, Simpson JR, Isacson O (1993) Age dependence of striatal neuronal death caused by mitochondrial dysfunction. NeuroReport 4:73-76.

Bowyer JF, Davies DL, Schmued L, Broening HW, Newport GD, Slikker Jr W, Holson RR (1994) Further studies of the role of hyperthermia in methamphetamine neurotoxicity. J Pharmacol Exp Ther 268:1571-1580.

Bowyer JF, Clausing P, Schmued L, Davies DL, Binienda Z, Newport GD, Scallet AC, Slikker Jr W (1996) Parenterally administered 3-nitropropionic acid and amphetamine can combine to produce damage to terminals and cell bodies in the striatum. Brain Res 712:221-229.

Bredt DS, Hwang PM, Snyder SH (1990) Localization of nitric oxide synthase indicating a neural role for nitric oxide. Nature 347:768-770.

Breese GR, Traylor TD (1970) Effect of 6-hydroxydopamine on brain norepinephrine and dopamine: evidence for selective degeneration of catecholamine neurons. J Pharmacol Exp Ther 174:413-420.
Brennan Jr WA, Bird ED, Aprille JR (1985) Regional mitochondrial respiratory activity in Huntington's disease brain. J Neurochem 44:1948-1950.

Brouillet E, Jenkins BG, Hyman BT, Ferrante RJ, Kowall NW, Srivastava R, Roy DS, Rosen BR, Beal MF (1993) Age-dependent vulnerability of the striatum to the mitochondrial toxin 3-nitropropionic acid. J Neurochem 60:356-359.

Brouillet E, Hantraye P, Ferrante RJ, Dolan R, Leroy-Willig A, Kowall NW, Beal MF (1995) Chronic mitochondrial energy impairment produces selective striatal degeneration and abnormal choreiform movements in primates. Proc Natl Acad Sci USA 92:7105-7109.

Brouillet E, Guyot MC, Mittoux V, Altairac S, Conde F, Palfi S, Hantraye P (1998) Partial inhibition of brain succinate dehydrogenase by 3-nitropropionic acid is sufficient to initiate striatal degeneration in rat brain. J Neurochem 70:794-805.

Butterworth J, Yates CM, Reynolds GP (1985) Distribution of phosphate-activated glutaminase, succinic dehydrogenase, pyruvate dehydrogenase, and gamma-glutamyl transpeptidase in postmortem brain from Huntington's disease and agonal cases. J Neurol Sci 67:161-171.

Cha JHJ, Kosinski CM, Kerner JA, Alsdorf SA, Mangiarini L, Davies SW, Penney JB, Bates GP, Young AB (1998) Altered brain neurotransmitter receptors in transgenic mice expressing a portion of an abnormal human Huntington disease gene. Proc Natl Acad Sci USA 95:6480-6485.

Chapman AG, Dürmuller N, Lees GJ, Meldrum BS (1989) Excitotoxicity of NMDA and kainic acid is modulated by nigrostriatal dopaminergic fibres. Neurosci Lett 107:256-260.

Cheng N-N, Maeda T, Kume T, Kaneko S, Kochiyama H, Akaike A, Goshima Y, Misu Y (1996) Differential neurotoxicity induced by L-DOPA and dopamine in cultured striatal neurons. Brain Res 743:278-283.

Cohen G, Heikkila RE (1974) The generation of hydrogen peroxide, superoxide radical, and hydroxyl radical by 6-hydroxydopamine, dialuric acid, and related cytotoxic agents. J Biol Chem 249:2447-2452.

Cotman CW, Monaghan DT, Ottersen OP, Storm-Mathisen J (1987) Anatomical organization of excitatory amino acid receptors and their pathways. Trends Neurosci 10:273-280.

Coyle JT, Schwarcz R (1976) Lesion of striatal neurones with kainic acid provides a model of Huntington's chorea. Nature 263:244-246.

Dunnett SB, Whishaw IQ, Rogers DC, Jones GH (1987) Dopamine-rich grafts ameliorate whole body motor symmetry and sensory neglect but not independent limb use in rats with 6-hydroxydopamine lesions. Brain Res 415:63-78.

Dunnett SB, Isacson O, Sirinathsinghji DJ, Clarke DJ, Björkland A (1988) Striatal grafts in rats with unilateral neostriatal lesions. III. Recovery from dopamine-dependent motor asymmetry and defects in skilled paw reaching. Neuroscience 24:813-820.

Ellison G, Eison MS, Huberman HS, Daniel F (1978) Long-term changes in dopaminergic innervation of caudate nucleus after continuous amphetamine administration. Science 201:276-278.

Erecinska M, Nelson D (1994) Effects of 3-nitropropionic acid on synaptosomal energy and transmitter metabolism: relevance to neurodegenerative brain diseases. J Neurochem 63:1033-1041.

Fallon JH, Loughlin SE (1995) Substantia nigra. In: The rat central nervous system (Paxinos G, ed), pp 215-237. London: Academic.

Ferrante RJ, Gutekunst C-A, Persichetti F, McNeil S, Kowall NW, Gusella JF, MacDonald ME, Beal MF, Hersch SM (1997) Heterogeneous topographic and cellular distribution of Huntingtin expression in the normal human neostriatum. J Neurosci 17:3052-3063.

Filloux F, Townsend JJ (1993) Pre- and postsynaptic neurotoxic effects of dopamine demonstrated by intrastriatal injection. Exp Neurol 119:79-88.

Filloux F, Wamsley JK (1991) Dopaminergic modulation of excitotoxicity in rat striatum: evidence from nigrostriatal lesions. Synapse 8:281-288.

Finnegan KT, Taraska T (1996) Effects of glutamate antagonists on methamphetamine and 3,4-methylenedioxymethamphetamine-induced striatal dopamine release in vivo. J Neurochem 66:1949-1958.

Fu Y, He F, Zhang S, Huang J, Zhang J, Jiao X (1995a) 3-Nitropropionic acid produces indirect excitotoxic damage to rat striatum. Neurotoxicol Teratol 17:333-339.

Fu Y-T, He F-S, Zhang S-L, Zhang J-S (1995b) Lipid peroxidation in rats intoxicated with 3-nitropropionic acid. Toxicon 33:327-331.

Fujiwara H (1992) Comparative studies of sulpiride and classical neuro- 
leptics on induction of catalepsy, locomotor activity, and brain dopamine metabolism in mice. Pharmacol Biochem Behav 41:301-308.

Galpern WR, Matthews RT, Beal MF, Isacson O (1996) NGF attenuates 3-nitrotyrosine formation in a 3-NP model of Huntington's disease. NeuroReport 7:2639-2642.

Garside S, Furtado JCS, Mazurek MF (1996) Dopamine-glutamate interactions in the striatum: behaviorally relevant modification of excitotoxicity by dopamine receptor-mediated mechanisms. Neuroscience 75:1065-1074.

Gibb JW, Johnson M, Hanson GR (1990) Neurochemical basis of neurotoxicity. Neurotoxicology 11:317-321.

Ginovart N, Lundin A, Farde L, Halldin C, Bäckman L, Swahn C-G, Pauli S, Sedvall G (1997) PET study of the pre- and post-synaptic dopaminergic markers for the neurodegenerative process in Huntington's disease. Brain 120:503-514.

Giovanni A, Liang LP, Hastings TG, Zigmond MJ (1995) Estimating hydroxyl radical content in rat brain using systemic and intraventricular salicylate: impact of methamphetamine. J Neurochem 64:1819-1825.

Globus Y-T, Busto R, Dietrich WD, Martinez E, Valdes I, Ginsberg MD (1988) Effect of ischemia on the in vivo release of striatal dopamine, glutamate, and $\gamma$-aminobutyric acid studied by intracerebral microdialysis. J Neurochem 51:1455-1464.

Gould DH, Gustine DL (1982) Basal ganglia degeneration, myelin alterations, and enzyme inhibition induced in mice by the plant toxin 3-nitropropanoic acid. Neuropathol Appl Neurobiol 8:377-393.

Gould DH, Wilson MP, Hamar DW (1985) Brain enzymes and clinical alterations induced in rats and mice by nitroalipatic toxicants. Toxicol Lett 27:83-89.

Graham DG (1978) Oxidative pathways for catecholamines in the genesis of neuromelanin and cytotoxic quinones. Mol Pharmacol 14:633-634.

Green AR, De Souza RJ, Williams JL, Murray TK, Cross AJ (1992) The neurotoxic effects of methamphetamine on 5-hydroxytryptamine and dopamine in brain: evidence for the protective effect of Chlor. Neuropharmacology 31:315-321.

Gu M, Gash MT, Mann VM, Javoy-Agid F, Cooper JM, Schapira AHV (1996) Mitochondrial defect in Huntington's disease caudate nucleus. Ann Neurol 39:385-389.

Hamilton BF, Gould DH (1987) Nature and distribution of brain lesions in rats intoxicated with 3-nitropropionic acid: a type of hypoxic (energy deficient) brain damage. Acta Neuropathol (Berl) 72:286-297.

Harms L, Meierkord H, Timm G, Pfeiffer L, Ludolph AC (1997) Decreased $N$-acetyl-aspartate/choline ratio and increased lactate in the frontal lobe of patients with Huntington's disease: a proton magnetic resonance spectroscopy study. J Neurol Neurosurg Psychiatry 62:27-30.

Harper PS (1996) Huntington's disease. London: Saunders.

Hastings TG, Lewis DA, Zigmond MJ (1996) Role of oxidation in the neurotoxic effects of intrastriatal dopamine injections. Proc Natl Acad Sci USA 93:1956-1961.

Hollis C, Strange PG (1992) Studies on the structure of the ligandbinding site of the brain $\mathrm{D}_{1}$ dopamine receptor. Biochem Pharmacol 44:325-334.

Hu X-T, White FJ (1997) Dopamine enhances glutamate-induced excitation of rat striatal neurons by cooperative activation of $\mathrm{D}_{1}$ and $\mathrm{D}_{2}$ class receptors. Neurosci Lett 224:61-65.

Jenkins BG, Koroshetz WJ, Beal MF, Rosen BR (1993) Evidence for impairment of energy metabolism in vivo in Huntington's disease using localized ${ }^{1} \mathrm{H}$ NMR spectroscopy. Neurology 43:2689-2695.

Koroshetz WJ, Jenkins B, Rosen B, Beal MF (1993) Ubiquinone lowers occipital lactate levels in patients with Huntington's disease. Neurology 43:A334.

Koroshetz WJ, Jenkins B, Rosen B, Beal MF (1994) Evidence for a metabolic disorder in Huntington's disease. Neurology 44:A338.

Koroshetz WJ, Jenkins BG, Rosen BR, Beal MF (1997) Energy metabolism defects in Huntington's disease and effects of coenzyme $Q_{10}$. Ann Neurol 41:160-165.

Ludolph AC, Seelig M, Ludolph A, Novitt P, Allen CN, Spencer PS, Sabri MI (1992) 3-Nitropropionic acid decreases cellular energy levels and causes neuronal degeneration in cortical explants. Neurodegeneration 1:155-161.

Mailman RB, Nichols DE, Tropsha A (1997) Molecular drug design and dopamine receptors. In: The dopamine receptors (Neve KA, Neve RL, eds), pp 105-134. Totowa, NJ: Humana.

McGeer EG, McGeer PL (1976) Duplication of biochemical changes of
Huntington's chorea by intrastriatal injections of glutamic and kainic acids. Nature 263:517-519.

McLaughlin BA, Nelson D, Erecinska M, Chesselet M-F (1998) Toxicity of dopamine to striatal neurons in vitro and potentiation of cell death by a mitochondrial inhibitor. J Neurochem 70:2406-2415.

Miller PJ, Zaborszky L (1997) 3-Nitropropionic acid neurotoxicity: visualization by silver staining and implications for use as an animal model of Huntington's disease. Exp Neurol 146:212-229.

Nakao N, Brundin P (1997) Effects of $\alpha$-phenyl-tert-butyl nitrone on neuronal survival and motor function following intrastriatal injections of quinolinate or 3-nitropropionic acid. Neuroscience 76:749-761.

Nash JF, Yamamoto BK (1993) Effect of D-amphetamine on the extracellular concentrations of glutamate and dopamine in iprindole-treated rats. Brain Res 627:1-8.

Nicoli F, Viondury J, Maloteaux JM, Delwaide C, Confortgouny S (1993) CSF and serum metabolic profile of patients with Huntington's chorea-a study by high-resolution proton NMR-spectroscopy and HPLC. Neurosci Lett 154:47-51.

Nishino H, Shimano Y, Kumazaki M, Sakurai T (1995) Chronically administered 3-nitropropionic acid induces striatal lesions attributed to dysfunction of the blood-brain barrier. Neurosci Lett 186:161-164.

Nony PA, Scallet AC, Rountree RL, Ye X, Binienda Z (1997) 3-Nitropropionic acid produces hypothermia and inhibits histochemical labeling of succinate dehydrogenase in rat brain. Soc Neurosci Abstr 22:855.5.

Novelli A, Reilly JA, Lysko PG, Henneberry RC (1988) Glutamate becomes neurotoxic via the $N$-methyl-D-aspartate receptor when intracellular energy levels are reduced. Brain Res 451:205-212.

O'Dell SJ, Weihmuller FB, Marshall JF (1993) Methamphetamineinduced dopamine overflow and injury to striatal dopamine terminals: attenuation by dopamine $\mathrm{D}_{1}$ or $\mathrm{D}_{2}$ antagonists. $\mathrm{J}$ Neurochem 60:1792-1799.

O’Dell SJ, Weihmuller FB, McPherson RJ, Marshall JF (1994) Excitotoxic striatal lesions protect against subsequent methamphetamineinduced dopamine depletions. J Pharmacol Exp Ther 269:1319-1325.

Palfi S, Guyot MC, Hantraye P, Altairac S, Brouillet E (1996) Characterization of the inhibition of brain succinate dehydrogenase after systemic administration of 3-nitropropionic acid. Soc Neurosci Abstr 21:735.5.

Parker Jr WD, Boyson SJ, Luder AS, Parks JK (1990) Evidence for a defect in NADH: ubiquinone oxidoreductase (complex I) in Huntington's disease. Neurology 40:1231-1234.

Pellegrino LJ, Cushman AJ (1967) A stereotaxic atlas of the rat brain. New York: Appleton-Century-Crofts.

Schmidt CJ, Ritter JK, Sonsalla PK, Hanson GR, Gibb JW (1985) Role of dopamine in the neurotoxic effects of methamphetamine. J Pharmacol Exp Ther 233:539-544.

Schulz JB, Matthews RT, Jenkins BG, Ferrante RJ, Siwek D, Henshaw DR, Cipolloni PB, Mecocci P, Kowall NW, Rosen BR, Beal MF (1995) Blockade of neuronal nitric oxide synthase protects against excitotoxicity in vivo. J Neurosci 15:8419-8429.

Schulz JB, Henshaw DR, MacGarvey U, Beal MF (1996) Involvement of oxidative stress in 3-nitropropionic acid neurotoxicity. Neurochem Int 29:167-171.

Sedvall G, Karlsson P, Lundin A, Anvret M, Suhara T, Halldin C, Farde $\mathrm{L}$ (1994) Dopamine $\mathrm{D}_{1}$ receptor number-a sensitive PET marker for early brain degeneration in Huntington's disease. Eur Arch Psychiatry Clin Neurosci 243:249-255.

Seiden LS, Ricaurte GA (1987) Neurotoxicity of methamphetamine and related drugs. In: Psychopharmacology: a third generation of progress (Meltzer HY, ed), pp 359-366. New York: Raven.

Seiden LS, Vosmer G (1984) Formation of 6-hydroxydopamine in caudate nucleus of the rat brain after a single large dose of methylamphetamine. Pharmacol Biochem Behav 21:29-31.

Sharp AH, Loev SJ, Schilling G, Li S-H, Li X-J, Bao J, Wagster MV, Kotzuk, JA, Steiner JP, Lo A, Hedreen J, Sisodia S, Snyder SH, Dawson TM, Ryugo DK, Ross CA (1995) Widespread expression of Huntington's disease gene (IT15) protein product. Neuron 14:1065-1074.

Sheng P, Cerruti C, Ali S, Cadet JL (1996) Nitric oxide is a mediator of methamphetamine (METH)-induced neurotoxicity. In vitro evidence from primary cultures of mesencephalic cells. Ann NY Acad Sci 801:174-186.

Shimano Y, Kumazaki M, Sakurai T, Hida H, Fujimoto I, Fukuda A, Nishino H (1995) Chronically administered 3-nitropropionic acid pro- 
duces selective lesions in the striatum and reduces muscle tonus. Obes Res 3:779S-784S.

Simpson JR, Isacson O (1993) Mitochondrial impairment reduces the threshold for in vivo NMDA-mediated neuronal death in the striatum. Exp Neurol 121:57-64.

Slivka A, Brannan TS, Weinberger J, Knott PJ, Cohen G (1988) Increase in extracellular dopamine in the striatum during cerebral ischemia: a study utilizing cerebral microdialysis. J Neurochem 50:1714-1718.

Sonsalla PK, Nicklas WJ, Heikkila RE (1989) Role for excitatory amino acids in methamphetamine-induced nigrostriatal dopaminergic toxicity. Science 243:398-400.

Sonsalla PK, Riordan DE, Heikkila RE (1991) Competitive and noncompetitive antagonists at $N$-methyl-D-aspartate receptors protect against methamphetamine-induced dopaminergic damage in mice. J Pharmacol Exp Ther 256:506-512.
Tsai MJ, Goh CC, Wan YL, Chang C (1997) Metabolic alterations produced by 3-nitropropionic acid in rat striata and cultured astrocytes: quantitative in vitro ${ }^{1} \mathrm{H}$ nuclear magnetic resonance spectroscopy and biochemical characterization. Neuroscience 79:819-826.

Tyler A, Scourfield J, Morris MR (1996) Management and therapy of Huntington's disease. In: Huntington's disease (Harper PS, ed), pp 161-201. London: Saunders.

Ungerstedt U, Arbuthnott GW (1970) Quantitative recording of rotational behavior in rats after 6-hydroxydopamine lesions of the nigrostriatal dopamine system. Brain Res 24:485-493.

Wüllner U, Young AB, Penney JB, Beal MF (1994) 3-Nitropropionic acid toxicity in the striatum. J Neurochem 63:1772-1781.

Weeks RA, Piccini P, Harding AE, Brooks DJ (1996) Striatal $D_{1}$ and $D_{2}$ dopamine receptor loss in asymptomatic mutation carriers of Huntington's disease. Ann Neurol 40:49-54. 